\title{
A gestão documental no Arquivo Municipal de Cariacica, Espírito Santo: novos rumos para um velho dilema
}

\section{Document management at the Municipal Archive of Cariacica, Espírito Santo, Brazil: new directions for an old dilemma}

\author{
Maira Cristina Grigoleto \\ Doutora em Ciência da Informação pela Universidade Estadual Paulista Júlio de Mesquita Filho (UNESP/Campus de Marília) \\ Prof a Adjunta do Departamento de Arquivologia e no Programa de Pós-Graduação em Ciência da Informação (PPGCI) da \\ Universidade Federal do Espírito Santo (UFES), Espírito Santo, Brasil \\ E-mail: magrigo@hotmail.com \\ Marcelo Calderari Miguel \\ Especialista em Educação Científica pela Universidade Federal de Minas Gerais (UFMG). \\ Pesquisador Programa Institucional de Iniciação Científica e Tecnológica, Universidade Federal do Espírito Santo (UFES), \\ Campus Universitário de Goiabeiras, Espírito Santo, Brasil \\ E-mail: marcelo.miguel@edu.ufes.br \\ Benedito José Simão \\ Bibliotecário pela Universidade Federal do Espírito Santo (UFES), Gerente do Arquivo - Prefeitura Municipal de Cariacica. \\ Pesquisador Programa Institucional de Iniciação Científica e Tecnológica, Universidade Federal do Espírito Santo (UFES), Campi \\ de Goiabeiras, Espírito Santo, Brasil \\ E-mail: bjorganizacoes@hotmail.com
}

\begin{abstract}
Resumo: Os arquivos públicos têm papel especial em gestões municipais tendo em vista a sua importância para a prestação de serviços aos cidadãos e para a tomada de decisões pelos gestores municipais. Com base nessa afirmação, o objetivo deste estudo é analisar, sob o prisma da gestão documental, a realidade arquivística em um contexto municipal. Trata-se de uma pesquisa qualitativa, através de um estudo de caso, por meio de levantamento bibliográfico. Após a análise dos dados coletados, pode-se dizer que o Arquivo Geral de Cariacica, no Estado do Espírito Santo, possui inúmeros problemas quanto a infraestrutura necessária para o tratamento dos documentos produzidos pela municipalidade. Conclui-se que há um longo caminho a ser percorrido para aprimorar a gestão de documentos na área municipal devido, principalmente, a escassez de recursos humanos, tecnológicos e financeiros.
\end{abstract}

Palavras-chave: Arquivo Público Municipal. Fundo Documental. Gestão Documental. Tabela de Temporalidade.

Abstract: Public archives have a special role in municipal administrations in view of their importance for the provision of services to citizens and for decision making by municipal administrators. Based on this statement, the objective of this study is to analyze, under the prism of document management, the archival reality in a municipal context. It is a qualitative research, through a case study, through a bibliographic survey. After analyzing the data collected, it can be said that the General Archive of Cariacica, in the State of Espírito Santo, has numerous problems regarding the necessary infrastructure for the treatment of documents produced by the municipality. It is concluded that there is a long way to go to improve the management of documents in the municipal area, mainly due to the scarcity of human, technological and financial resources.

Keywords: Municipal Public Archive. Documentary Fund. Document management. Temporality Table. 


\title{
1 Introdução
}

Os arquivos são importantes pelas diferentes funções que desempenham nas sociedades, exercendo papel fundamental para o bom funcionamento de administrações públicas e privadas. Cabe também mencionar as suas funcionalidades para sustentar direitos e deveres, seja por parte dos cidadãos ou do governo.

A concepção de Cortes (2011) sobre a justificativa para a existência dos arquivos é oportuna nesse momento introdutório. Para a autora, a existência dos arquivos justifica-se mais pela "difusão da informação" do que pela sua condição de "repositório de informações". Desse modo, compreende que "[...] é preciso transmitir conhecimento e possibilitar acesso aos usuários." (CORTES, 2011, p. 10).

Schäfer e Lima (2012, p. 140) apresentam que as organizações públicas e privadas buscam meios de gerenciar seus ativos informacionais, o que as torna um real centro de informações e conhecimento compostos por cadeias de bits. Para os autores, a "necessidade da gestão documental" assume maior relevância nas organizações públicas, pois as informações produzidas e a custodiadas por elas são representações do caráter público e social, que precisam servir a coletividade, ou seja, ao bem comum. Por conseguinte, apontam que:

\begin{abstract}
Nas organizações públicas, as mudanças ocorrem em um ritmo lento, demandando ações e projetos adequadamente planejados, que tenham por finalidade o acesso, promoção e uso racional das informações. Com a crescente quantidade de iniciativas, visando ao reconhecimento do valor da informação arquivística, inicia-se um despertar na consciência dos gestores públicos frente ao tema, criando perspectivas propícias à atuação dos arquivistas (SCHÄFER; LIMA, 2012, p. 141).
\end{abstract}

Em suma, a gestão de documentos arquivísticos pauta-se na aplicação de funções arquivísticas (criação, avaliação, aquisição, conservação, classificação, descrição e comunicação) que promovem o controle das informações, desde sua criação até a destinação final dos documentos (SCHÄFER; LIMA, 2012). Nessa via, este trabalho visa discutir a gestão documental no arquivo público, desenvolvendo-se em um estudo de caso realizado no Arquivo da Prefeitura Municipal de Cariacica, no Estado do Espírito Santo (ES).

Segundo o Dicionário Brasileiro de Terminologia Arquivística (ARQUIVO NACIONAL, 2005, p. 33), arquivo municipal é definido como “Arquivo público mantido pela administração 
municipal, identificado como o principal agente da política arquivística nesse âmbito.” Para Machado e Camargo (2000, p. 14) os arquivos públicos municipais são instituições responsáveis pelos “[...] conjuntos de documentos acumulados por órgãos dos poderes executivo e legislativo, no âmbito da administração municipal direta ou indireta".

Silva (2020, p. 81) assinala que "[...] o arquivo municipal é um serviço público de caráter administrativo, especializado na gestão e tratamento dos documentos, que também os custodia e divulga". O autor aborda ainda sobre a característica complexa da instituição "Arquivo", responsável tanto pela custódia de documentos de valor histórico-cultural quanto "[...] pela implantação dos serviços arquivísticos de gestão documental nos órgãos da administração pública municipal." (SILVA, 2020, p. 83).

Em diálogo com o apresentado, esse estudo adentra no panorama do Arquivo Municipal e a problemática de pesquisa envolve a gestão documental sobre o prisma da legislação arquivística. Assim, o objetivo geral é analisar a realidade da gestão documental em um contexto municipal. Nessa esfera, os objetivos específicos são: compreender práticas de gestão documental no Arquivo de Cariacica/ES; e identificar como essa instituição, responsável por custodiar e gerir toda a documentação de valores administrativos e histórico-culturais da Prefeitura de Cariacica opera com os recursos disponíveis.

Destarte, a motivação de investigação evoca um importante Arquivo do executivo - ora nomeado como Arquivo Geral de Cariacica - na Região Metropolitana da Grande Vitória (RMGV) que vem percorrendo um caminho para se modernizar. Dessa forma, enfatizam-se as ações que justificam a locação do imóvel do Arquivo e os cardeais direcionamentos do adequado agir arquivístico desde a produção documental. Além disso, é importante frisar que o “[...] conhecimento relativo ao arquivo municipal é pertinente e se justifica pela escassez de pesquisas sobre o tema nos programas de pós-graduação e pouco veiculado em congressos, apesar de possuir um espaço no Congresso Nacional de Arquivologia (CNA)" (SILVA, 2020, p. 81).

Mediante o exposto, abordaremos primeiramente a gestão documental e as práticas arquivísticas do Arquivo de Cariacica (Espírito Santo), bem como a sua função na gestão de documentos do município, interrelacionando com aspectos da legislação arquivística brasileira. Em seguida, tratar-se-á do papel do Arquivo Municipal para a sociedade, em específico, pelas atividades de empowerment ou empoderamento - que expressa a atuação que melhora a qualidade das atividades, 
fazendo com que o resultado do serviço prestado seja satisfatoriamente melhor. Posto isso, entendese que:

\begin{abstract}
Quando surgiram as primeiras instituições públicas, elas foram definidas e defendidas como sustentáculos dos direitos do cidadão e do Estado e como laboratórios da história. A razão de ser do arquivar e dos arquivos era atender os interesses do direito, da administração e da história. As discussões contemporâneas ligam os objetivos dos arquivos e o papel das instituições arquivísticas a necessidade de interesses sociais definidos de forma mais ampla e giram em torno de questões relacionadas à responsabilidade, à identidade, à inclusão e à justiça social. A noção de arquivo como "arsenal para responsabilidade" e como "lugar de memória coletiva" inclui essa perspectiva mais ampla (MACNEIL, 2016, p. 8).
\end{abstract}

Acredita-se que um oportuno, desejado e factível salto de qualidade dependerá também da solução desses problemas de infraestrutura e, sobretudo, da implementação de políticas públicas arquivísticas e de informação. Nessa via, a conclusão indica os aspectos legais que servem para aprimorar a gestão dessa instituição arquivística e para que a mesma execute a custódia de toda a documentação referente ao município, assegurando a preservação e o acesso às informações por parte do cidadão, além de garantir a memória do município via o alcance ao rol de documentos e informações.

\title{
$2 \mathrm{O}$ arquivo público municipal: dilemas e desafios
}

A seguir se explana a importância da gestão e das práticas arquivísticas para situar questões referentes aos arquivos público no âmbito geral e no contexto de Cariacica (ES).

\subsection{A gestão de documentos e as práticas arquivísticas}

A gestão de documentos e de informações em uma organização compreende práticas arquivísticas que englobam ações sobre documentos desde a sua produção até a destinação final (preservação ou eliminação). A finalidade dessas ações é garantir aos usuários o acesso às informações materializadas nos documentos, as quais são necessárias para a tomada de decisões, independente da fase do ciclo de vida em que os documentos se encontrem. Além disso, os procedimentos de gestão funcionam 


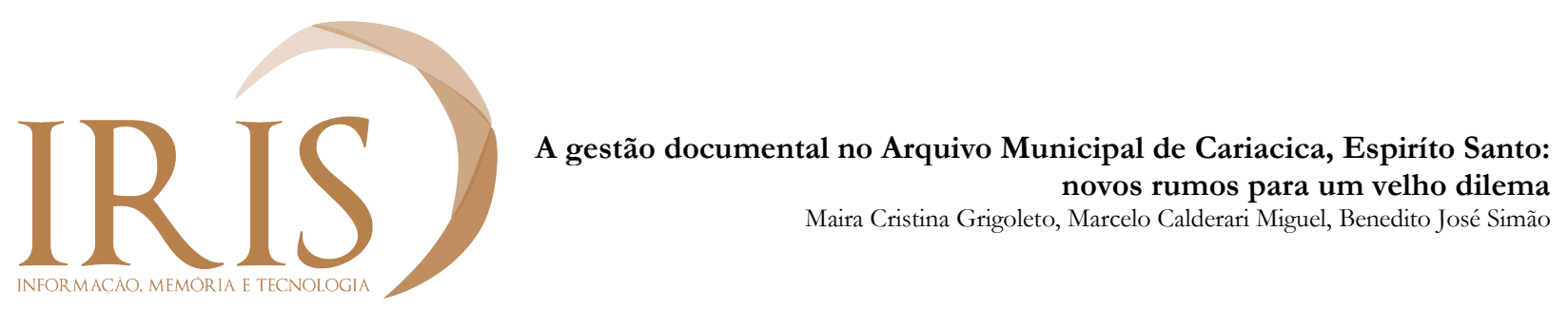

para a alocação da valorização dos documentos pelas categorias de valor administrativo, probatório, informativo e histórico-cultural. Para esclarecimento,

\begin{abstract}
As atividades ou práticas exercidas nos Arquivos, por meio do arquivista e sua equipe, estão inseridas nas especificações de cada fase dos Arquivos. As funções arquivísticas adotadas nas fases corrente e intermediária são realizadas pelos procedimentos da gestão de documentos. Nos arquivos permanentes são realizadas medidas de preservação, conservação, tratamento do documento para sua armazenagem e, atualização e ressignificação contínua. (FEITOZA; DUARTE, 2020, p. 216).
\end{abstract}

Feitoza e Duarte (2020), ao refletirem sobre as Memórias Organizacionais e Institucionais pelos vieses da Ciência da Informação, da Gestão e da Arquivologia, consideram que a partir de políticas de gestão organizacional e de Arquivos definidas pelas organizações - que envolvem as práticas arquivísticas de avaliação, seleção e análise de documentos - situam-se as possibilidades para a criação de espaços que integrem todo tipo de informação e conhecimento produzido dentro e fora do contexto organizacional.

\footnotetext{
Várias são as práticas arquivísticas que podem subsidiar com a gestão e preservação da memória nos espaços organizacionais e podemos destacar a história oral, a descrição, o arranjo, a taxonomia, a conservação, a preservação, a difusão e a disseminação e a avalição, como citada anteriormente. Essas funções lidam diretamente com os arquivos permanentes e potencializam a formação da memória no contexto organizacional (FEITOZA; DUARTE, 2020, p. 223).
}

Entende-se pelos encaminhamentos dos autores que, nos espaços criados em lugares institucionais, é possível a inclusão e validação de documentos de naturezas diversas desde que atendam às diversas valorizações e demandas de usos dos "[...] registros que foram produzidos no passado, como também os que são criados no presente e no futuro." (FEITOZA; DUARTE, 2020, p. 223).

Dentre abordagens recentes sobre a gestão de documentos está a ênfase de Rocha e Schmidt (2019) quanto a necessidade de tratamento documental desde a sua produção até a destinação final. Para as pesquisadoras, a classificação é função essencial na gestão de documentos. Em suas análises inferem sobre o impacto negativo em instituições onde não há a classificação de documentos e os comprometimentos em toda a cadeia de gestão de documentos arquivísticos. 
Para Rocha e Schmidt (2019) a classificação é a função arquivística que, ao lado da Avaliação e da Descrição, compõe a tríade de atividades capitais da prática arquivística. Dentre essas funções, a classificação desempenha um papel primordial como requisito que antecede às demais na gestão de documentos (ROCHA; SCHMIDT, 2019). Em suma, as autoras analisam que o plano de classificação de documentos é um instrumento de extrema relevância, constituindo a materialização da organicidade da produção documental, das ações que geram os documentos e, consequentemente, daquilo que estes documentos são capazes de provar, em outras palavras, seu valor probatório.

Expor a gestão de documentos cunhada em modelo estrutural-funcionalista e estruturalista influencia sobremaneira as práticas arquivísticas, forjando uma orientação baseada nos cuidados com a Tipologia Documental. De tal modo, os documentos arquivísticos têm de se manter acessíveis e utilizáveis pelo tempo que forem necessários, garantindo-se sua longevidade, funcionalidade e acesso contínuo. Dessa forma, a pesquisa de Faben e Rodrigues (2019, p. 170) indica que pela

Qualidade exclusiva dos documentos de arquivo, a organicidade é revelada pela Tipologia Documental, quando a ação que deu origem ao documento é vinculada à atividade e/ou função que o produziu. É por isso que a teoria arquivística se concentra no elo vital entre atividade funcional e o documento de arquivo [...].

Os autores consideram que "[...] identificar o documento de arquivo dentro do seu contexto de produção, como prova da ação que determina sua criação, bem como nomear os tipos documentais que compõem as séries, é um desafio e exige um trabalho de pesquisa do arquivista." (FABEN; RODRIGUES, 2019, p. 173).

Faben e Rodrigues (2020, p. 177) explicam que o tipo documental, não é “[...] qualquer nome, bem como não é o nome do título do documento de arquivo. Ele é a prova do cumprimento de uma atividade". Por isso afirmam que o agrupamento “[...] tipológico dos documentos de arquivo permite que o tratamento técnico arquivístico incida sobre a série documental tipológica, conferindo rigor e qualidade ao tratamento técnico arquivístico" (FABEN; RODRIGUES, 2020, p. 178). 


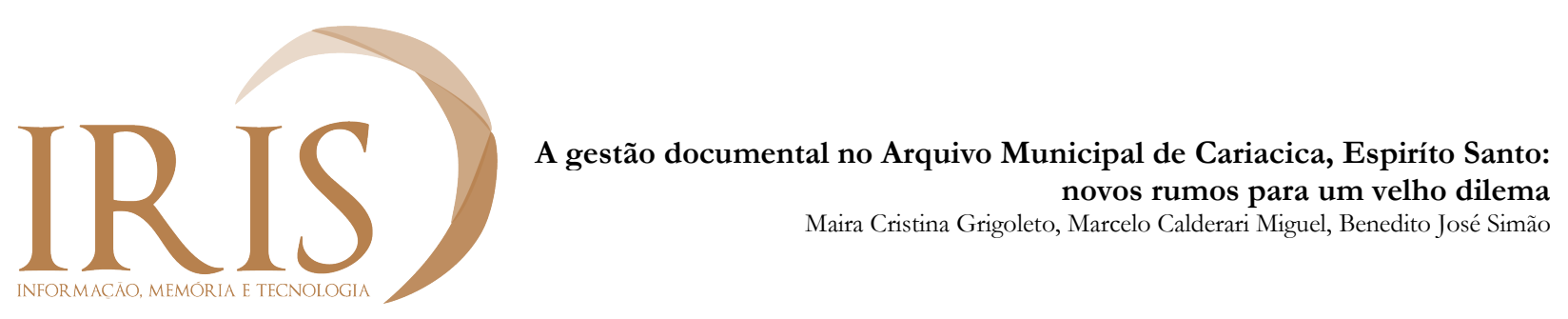

\section{$2.2 \mathrm{O}$ arquivo público municipal}

A importância dos arquivos tem sido objeto de estudos e discussões crescentes na interdisciplinaridade com a Ciência da Informação. No início da década de 2000, Fernández (2003) frisou que, primeiramente, os arquivos podem ser compreendidos como elementos efetivos dos sistemas de informação. Em segundo lugar, que a existência dos arquivos assevera a consonância com o direito constitucional à informação que assiste a todos os cidadãos; e, em terceiro lugar, que são imprescindíveis para exercer as funções de prestação de contas, transparência e continuidade na gestão pública.

Ao longo do tempo, os arquivos se transformaram, os suportes documentais se distinguiram e os métodos de organização dos acervos de documentos "evoluíram". Nesse sentido, Barros e Amélia (2009, p. 56) apontam que os arquivos se tornaram:

[...] parte constitutiva da sociedade da informação por buscar uma atuação em consonância com as tendências tecnológica e científica da sociedade, ou seja, em função de as tecnologias de informação não limitarem os conceitos do mundo vivenciado pelo ator social, uma vez que este ocupa vários espaços ao mesmo tempo, potencializando, assim, a transmissão da informação [...]. Nesse sentido, o Arquivo potencializa-se, seja por assumir novas funções, seja por renová-las, pois, além de coletar, salvaguardar, preservar, armazenar e disseminar a informação - funções tradicionais - proporciona sua reorganização em face às TI's, de forma a promover o encontro do cidadão com a informação.

O Conselho Nacional de Arquivos, na publicação 'Subsídios para a implantação de uma política municipal de arquivos: o arquivo municipal a serviço dos cidadãos’ (CONSELHO..., 2000, p. 07-08), assinala que o arquivo municipal é a instituição responsável pelo conjunto de documentos produzidos, recebidos e acumulados pela municipalidade, ou seja, pelos poderes executivos e legislativos do município, representados, concomitantemente, pela Prefeitura e a Câmara de Vereadores.

A Lei $\mathrm{n}^{\circ}$ 8.159/1991, que versa sobre a política nacional de arquivos públicos e privados, estabelece no art. $1^{\circ}$ que: "É dever do Poder Público a gestão documental e a proteção especial a documentos de arquivos, como instrumento de apoio à administração, à cultura, ao desenvolvimento científico e como elementos de prova e informação.” (BRASIL, 1991, p. 1).

Posteriormente, o Decreto $n^{\circ} 4.073 / 2002$, que regulamenta a Lei $n^{\circ} 8.159 / 1991$, institui o Conselho Nacional de Arquivos como órgão colegiado vinculado ao Ministério da Justiça e 
Segurança Pública (MJSP), que tem por finalidade definir a política nacional de arquivos públicos e privados no Brasil. Assim, entre as competências desse Conselho está a incumbência de estimular programas de gestão e de preservação de documentos públicos nos âmbitos federal, estadual, distrital e municipal, produzidos ou recebidos pelo Poder Público. Além disso, deve estimular a implantação de sistemas de Arquivos nos Poderes Executivo e Legislativo dos Municípios para a integração e modernização dos arquivos públicos e privados (BRASIL, 2002, p.1).

O CONARQ durante a década de 2010 desenvolveu campanhas para a conscientização e sensibilização junto aos prefeitos e presidentes de câmaras municipais sobre a importância da criação de Arquivos Públicos Municipais, culminando na publicação do material 'Criação e Desenvolvimento de Arquivos Públicos Municipais: transparência e acesso à informação para o exercício da cidadania (CONSELHO..., 2014).

A criação e desenvolvimento de arquivos públicos municipais garantem o suporte para programas de gestão de documentos e informações públicas no âmbito das prefeituras e das câmaras de vereadores. O arquivo público municipal é a Instituição que tem por finalidade implementar, avaliar e monitorar políticas públicas de gestão de documentos e informações por meio de programas de gestão, tratamento técnico, transferência, recolhimento, preservação, disponibilização e divulgação de documentos e informações produzidas, recebidos e acumulados pelo poder público municipal, em qualquer suporte ou formato (CANALI, 2017). Nesse painel, Silva (2020, p. 81) concebe que o arquivo “[...] demanda um orçamento com uma rubrica própria e com uma lei que o reconheça como uma instituição independente - suplementar ao governo municipal instituída por decretos ou resoluções".

Desse modo, o arquivo municipal destaca-se como um órgão indispensável para o planejamento, controle, transparência, eficácia e efetividade da administração municipal, assegurando o cumprimento da Constituição Federal.

No entanto é preciso compreender o duplo papel que os Arquivos desempenham (administrativo e sociocultural). Diferente do que aconteceu, para que ocorra sua formalização é necessária que o prefeito comunique à Câmara Municipal por meio de um projeto de lei específico a criação do Arquivo Público Municipal, com o intuito de implantar uma política municipal de arquivos (LORENZI, 2017, p. 21).

Logo, o município que tem um arquivo público institucionalizado em sua estrutura administrativa cumpre os preceitos da Constituição Federal (BRASIL, 1988) e da Lei de Arquivos 
(BRASIL, 1991), viabilizando a aplicabilidade dos seguintes dispositivos legais que corroboram a elucidação da responsabilidade penal, civil e administrativa: Lei Complementar nº 101/2000 e Lei Complementar $n^{\circ}$ 131/2009, que tratam sobre responsabilidade fiscal; e Lei $n^{\circ} 12.527 / 2011$, conhecida como Lei de Acesso à Informação. Essas medidas têm fortalecido, sobremaneira, a participação do cidadão na gestão pública, contudo Carli e Fachin (2017) apresentam que o cenário ainda provoca uma série de incertezas e desafios:

Resta saber se no Brasil, em um curto período de tempo, haverá mudanças profundas e maior valorização, assim como investimentos nos Arquivos Públicos pelas instituições governamentais e, consequentemente, mais confiança por parte dos cidadãos por meio dos serviços prestados pelos Arquivos. Acredita-se que a aprovação da Lei de Acesso à Informação será um desafio para os governos e os gestores de Arquivos, detentores de informações públicas (CARLI; FACHIN, 2017, p. 55).

Com a promulgação da Lei de Acesso à Informação, a gestão da documentação pública recebeu maior destaque, com vistas à penalidade legal. Grosso modo, o arquivo municipal é um órgão especificamente dedicado e responsável pelo conjunto de documentos produzidos, recebidos e acumulados por órgãos públicos municipais no exercício de suas atividades, constituindo-se em uma importante fonte de informação (CANALI, 2017).

Como tratado anteriormente, o arquivo público de um município é essencial para a garantia dos direitos à memória e à informação, os quais podem ser contemplados pela boa governança e pelo atendimento de demandas informacionais relacionadas à cidadania (CONSELHO..., 2020). Nesse aspecto, conforme apresentado por Canali (2017, online), pode-se citar as demandas relacionadas às “[...] informações sobre os atos governamentais, andamento e solução de questões administrativas, econômicas e jurídicas, bem como informações sobre saúde, educação, meio ambiente, raízes históricas do município.” 


\subsection{O Arquivo Geral de Cariacica}

O Arquivo Municipal de Cariacica, conhecido como Arquivo Geral de Cariacica, foi criado em 1987 com a missão de administrar e preservar todos os documentos gerados pelo Município. Vinculado à Secretaria Municipal de Administração (SEMAD), está subordinado à Gerência de Apoio Logístico, cuja missão é comandar, coordenar e supervisionar a gestão das atividades e serviços de protocolo, de Arquivo, de edição e de publicação dos atos oficiais, de frota de veículos e serviços correlatos.

Quadro 1 - Identidade organizacional do Arquivo Geral de Cariacica (ES).

Arquivo Geral de Cariacica - AGC

\begin{tabular}{ll}
\hline CODEARQ: & BR ESAGC \\
\hline Endereço: & Rodovia BR 262. Km 2,5. Trevo Alto Laje. Cariacica (ES). \\
\hline URL: & http://www.cariacica.es.gov.br/ \\
\hline Ano de Criação: & 1987 \\
\hline Vinculação Administrativa: & Secretaria Municipal de Administração \\
\hline Missão Institucional: & A PMC tem por objetivo administrar o Município. \\
\hline $\begin{array}{l}\text { Caracterização do acervo: } \\
\text { Condições de acesso aos } \\
\text { documentos: }\end{array}$ & $\begin{array}{l}\text { O acervo tem como especialidade a guarda e a preservação dos documentos } \\
\text { administrativos do Município. }\end{array}$ \\
\hline
\end{tabular}

Fonte: os autores, 2020 com base nos dados disponibilizados pelo CONARQ em seu sítio eletrônico. ${ }^{1}$

Quanto ao espaço físico, o Arquivo Geral de Cariacica está abrigado em imóvel locado pela Prefeitura Municipal, que foi selecionado pela Secretaria de Administração de Cariacica por meio do Edital de Chamada Pública no 20/2014 vinculado ao Processo no 33076/2014/SEMAD. Conforme características e condições previamente estabelecidas nesse Edital, dentre os requisitos mínimos do imóvel para atender às necessidades do Arquivo Público destacam-se: contar com uma área construída de no mínimo $2000 \mathrm{~m}^{2}$ (dois mil metros quadrados); possuir área reservada ao trabalho técnico para comportar o depósito de documentos; e dispor de área administrativa que permita acessibilidade voltada às pessoas com deficiência $(\mathrm{PcD})$. Em entrevista realizada com a equipe do Arquivo Geral de Cariacica em novembro de 2020, obteve-se alguns dados sobre as características do imóvel em questão conforme explicitado no Quadro 2.

1 Disponível em: https://www.gov.br/conarq/pt-br/servicos-1/consulta-as-entidades-custodiadoras-de-acervosarquivisticos-cadastradas/entidades-custodiadoras-no-estado-do-espirito-santo/arquivo-geral-de-cariacica. Acesso em: 10 jan. 2021. 


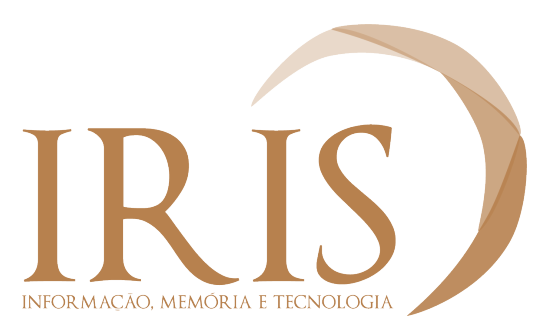

A gestão documental no Arquivo Municipal de Cariacica, Espiríto Santo: novos rumos para um velho dilema Maira Cristina Grigoleto, Marcelo Calderari Miguel, Benedito José Simão

Quadro 2 - Características da Edificação do Arquivo de Cariacica (ES).

\begin{tabular}{|l|l|}
\hline Pé Direito & A altura em torno de 2,70m (dois metros e setenta centímetros). \\
\hline Piso & Boas condições de piso frio ou vinílico homogêneo. \\
\hline Pintura & $\begin{array}{l}\text { Externa e interna com tinta antimofo de cor clara (fórmula fungicida e bactericida que ajudam a } \\
\text { conservar as superfícies expostas à umidade). }\end{array}$ \\
\hline $\begin{array}{l}\text { Instalações } \\
\text { Elétricas }\end{array}$ & De acordo com as normas técnicas em vigor. \\
\hline Porta De Entrada & $\begin{array}{l}\text { Conforme parâmetros de acessibilidade onde o seu vão livre deve ter a medida de 0,80m (oitenta } \\
\text { centímetros) e altura mínima de 2,10m; }\end{array}$ \\
\hline Local & $\begin{array}{l}\text { Fora de áreas próximas a linhas férreas, de terrenos em que possam ocorrer alagamentos ou } \\
\text { deslizamentos de terra, bem como não deve apresentar vazamentos de água em sua cobertura ou } \\
\text { laje e nem umidade nas paredes decorrente de infiltrações. }\end{array}$ \\
\hline Localização & $\begin{array}{l}\text { Próxima a sede da Prefeitura Municipal de Cariacica, localizada à Rodovia BR 262, no 3.700, Km } \\
\text { 3,0, Bairro Alto Lage - distância máxima de 5 (cinco) quilômetros. }\end{array}$ \\
\hline $\begin{array}{l}\text { Vigência do } \\
\text { Contrato }\end{array}$ & O contrato de locação tem a vigência de 60 (sessenta) meses, \\
\hline
\end{tabular}

Fonte: os autores, com base em entrevistas realizadas com a equipe do arquivo em nov. 2020.

Compreende-se que o espaço físico faz muita diferença no universo dos diferentes usuários do arquivo, que podem ser os profissionais que atuam com o tratamento dos acervos bem como os usuários. Para tanto, realiza-se uma breve apresentação da estrutura física, conforme edificação que abriga os conjuntos documentais da Prefeitura Municipal ilustrada a seguir (Figura 1).

Figura 1 - Arquivo acondicionada e estrutura do prédio onde se instala o Arquivo Público de Cariacica

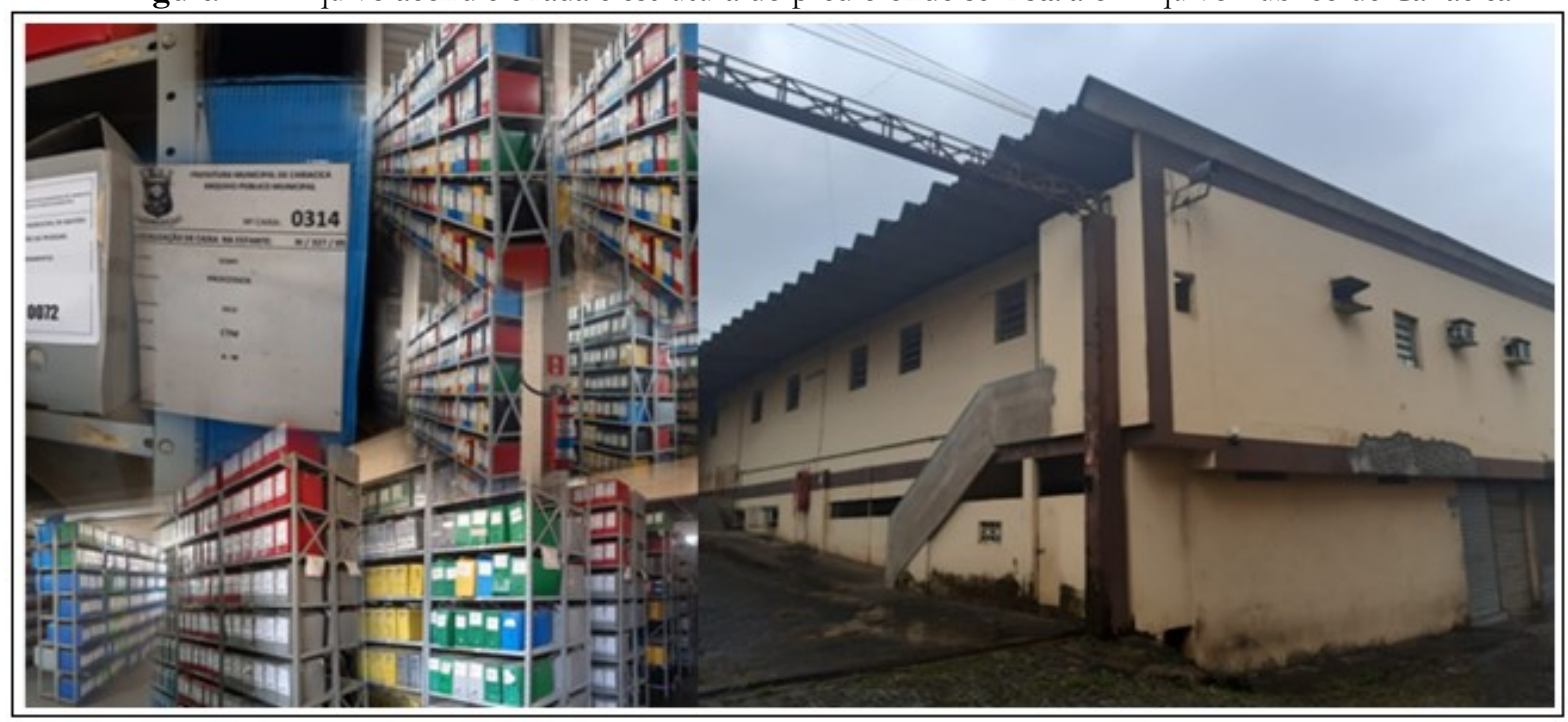

Fonte: os autores, Arquivo de Municipal - Bairro Vila Independência, Cariacica/ES, nov. 2020. 
Por meio da Figura 1 é possível situar que os documentos são acondicionados em estantes de aço e, além disso, que são arquivados em caixas plásticas de polionda - com diversas cores que identificam as secretárias de origem. Cabe mencionar que os mesmos são recolhidos pelo Arquivo Geral de Cariacica com classificação e organização prévias para facilitar a recuperação quando necessária.

Os tipos documentais que se encontram no acervo dessa instituição são: Contratos, Fichas de professores, Fichas de empenho, Ordens de pagamento, Folhas de pagamento de professores, Recibos de documentos, Prestação de contas, Cadastro rural, Ofícios recebidos, Fichas de credores, Requerimentos diversos, Guias de recolhimento, Boletins e balancetes, Cadastro de terrenos, Certidões negativas de arrecadação, Impostos sobre venda e varejo de combustível, Correspondências expedidas, Portarias e protocolos, Fichas rurais, Fichas de impostos, Alvarás de licença, Processos trabalhistas encerrados, Fichas de controle, entre outros.

Sobre os instrumentos de gestão documental, o Plano de Classificação de Documentos e a Tabela de Temporalidade do Município de Cariacica foram instituídos pelo Decreto no 069/2019. No mesmo ano, pelo Decreto $n^{\circ} 111 / 2019$, foi criada a Comissão Permanente de Avaliação de Documentos com a finalidade "[...] viabilizar, treinar e acompanhar a avaliação e descarte dos documentos públicos [...]”. (CARIACICA, 2019).

\section{Procedimentos metodológicos}

O presente estudo trata-se de uma pesquisa exploratória descritiva que, segundo Hair Junior et al. (2007), é particularmente útil quando o responsável pelas decisões dispõe de poucas informações, podendo assim considerar que os planos exploratórios são orientados para a descoberta. Para esses pesquisadores a pesquisa exploratória pode assumir várias formas, o que pode ser facilitado por uma completa revisão da literatura. Nessa pesquisa em especial, se leu inúmeros textos que abordam a gestão pública documental, com temas relacionados à gestão pública, Arquivos públicos, implantação de Arquivos públicos. Tratou-se ainda de temas sobre o Plano de Classificação e Tabela de Temporalidade de Documentos de Arquivos Municipais.

Trivinõs (2007) reporta que estudos exploratórios permitem ao investigador aumentar sua experiência em torno de determinado problema, sendo que o pesquisador parte de uma hipótese e aprofunda seu estudo, a fim de planejar uma pesquisa descritiva. Assim, o estudo pode ser 
considerado como uma pesquisa descritiva, já que, segundo Hair Junior et al. (2007) os planos de pesquisa descritiva em geral são estruturados e especificamente criados para medir as características descritas em uma questão de pesquisa.

O local em que se propôs a pesquisa foi a Prefeitura de Cariacica, onde se encontraram os documentos referentes ao município. Logo, o presente estudo é um estudo de caso, pois há uma delimitação no espaço e um estudo e conhecimento deste lugar em particular (GIL, 2009). Em relação ao método de pesquisa, o um estudo de caso, permitem uma visão global do problema e possibilita identificar fatores que influenciam ou são por eles influenciados.

Complementando essa ideia, para Cooper e Schindler (2011) o estudo de caso é uma metodologia de pesquisa poderosa que combina entrevistas individuais e às vezes em grupo com análise de registro e observação direta, cujo objetivo é obter perspectivas múltiplas de uma única organização, situação, evento ou processo em um ponto no tempo ou por um período de tempo, sendo utilizada também para entender processos específicos.

A abordagem do problema ocorre de forma qualitativa, visto que "a pesquisa qualitativa responde a questões muito particulares. Ela se ocupa, nas Ciências Sociais, com um nível de realidade que não pode ou não deveria ser quantificado", conforme reporta Minayo (1994, p. 21).

\section{Apresentação e análise dos resultados}

$\mathrm{Na}$ esfera municipal o fortalecimento de campanhas em prol dos arquivos públicos foi realizado pelo Conselho Nacional de Arquivos (CONARQ) no sentido de "[...] informar e sensibilizar as autoridades públicas municipais e também os cidadãos acerca da importância dos Arquivos públicos para a boa governança, construção da memória e preservação da identidade histórica e cultural da comunidade local". (CONSELHO..., 2020, online). Além disso, essas campanhas ressaltam-se a relevância

[...] da implementação de programas de gestão de documentos e informações públicas no âmbito das prefeituras e das câmaras de vereadores, com a finalidade de apoiar os municípios brasileiros a tornar a administração pública municipal mais transparente e eficaz, garantindo dessa forma o direito de acesso às informações e servindo como instrumento para o exercício pleno da cidadania (CONSELHO...., 2020, online). 
Ao refletirem sobre os apontamentos do CONARQ em 2000, Pedrazzi e Pavão (2018, p. 179) asseveram que “[...] as dificuldades com o tratamento documental só mudará (sic) quando os governantes municipais se convencerem de que os conjuntos documentais registram as manifestações de pessoas, instituições públicas e privadas.”

Deve-se sinalizar que os documentos são uma espécie de produto necessário do funcionamento de cada órgão e "[...] ao mesmo tempo em que constituem instrumentos ou veículos da ação do governo municipal, os documentos testemunham as relações deste com a comunidade a que serve, daí o interesse em garantir sua adequada gestão e manutenção para as instituições e para os munícipes.” (MACHADO; CAMARGO, 2000, p. 17).

Sobre o pessoal com qualificação técnica e intelectual para trabalhar com acervos documentais, compreende-se que é necessária uma ação mais efetiva dos cursos de Arquivologia e do próprio Arquivo Nacional junto às prefeituras no intuito de divulgar as competências necessárias aos profissionais que atuarão nessas instituições. Corroborando como essas questões, Faben e Rodrigues (2020, p. 177) reforçam que

[...] o único profissional capaz de nomear o documento de arquivo a partir da sua razão de ser é o arquivista com conhecimento dos princípios, conceitos e métodos da Diplomática, base teórica da identificação arquivística realizada nos parâmetros da Tipologia Documental.

Segundo o CONARQ (2000), no momento de implantação de um arquivo municipal, é necessário certo quantitativo de funcionários para realizarem as atividades administrativas e de apoio técnico. Para tanto, deve-se prever profissionais de nível superior e médio para desenvolverem as atividades de gestão documental (produção, registro, tramitação, classificação, arquivamento, avaliação, destinação e orientação aos arquivos setoriais da prefeitura) bem como de arquivamento permanente (arranjo, descrição, conservação, reprodução, divulgação e acesso aos documentos).

\subsection{Particularidades da Gestão de Documentos no Arquivo de Cariacica}

Sobre a realidade da Prefeitura de Cariacica, verificou-se que atualmente essa conta com dois arquivistas que respondem pelo funcionamento do Arquivo Geral e coordenam as atividades de atendimento das demandas dos usuários, bem como as de preservação histórica da documentação pública gerada pela Prefeitura. 
Além disso, o Município possui serviço de protocolo que é incumbido do registro, classificação, distribuição, controle da tramitação e expedição de documentos produzidos pelos diferentes setores. Quanto ao acesso às informações da Prefeitura por parte dos cidadãos, de forma presencial, qualquer pessoa que formalmente solicite alguma informação será atendida da forma mais eficaz possível, de maneira que sane as suas necessidades. De forma virtual, está disponibilizada uma página na internet que fornece a todos os munícipes e cidadãos interessados, com informações atualizadas sobre publicações das principais atividades realizadas, bem como de dados sobre a forma de governo, sobre o município e sobre as principais normas e atos.

Ao observar a forma de armazenamento utilizada no Arquivo Geral de Cariacica, verificouse o uso de estantes pintadas e construídas com aço, sem indício de ferrugem. As mesmas apresentam bastante resistência e acomodam de forma correta as caixas-arquivo. No entanto, constatou-se a insuficiência de mobiliário para todo o acervo, visto que parte da documentação se encontra exposta a agentes físicos de deterioração de documentos, tais como: iluminação, temperatura e umidade.

Foi possível averiguar que há preocupação em proteger os documentos contra possíveis danos ao acondicioná-los em caixas-arquivo de polionda. No entanto, é considerável sinalizar que parte dessas caixas encontra-se em más condições de conservação, o que as torna frágeis e pouco resistentes. Assim, apesar de os documentos possuírem um método de acondicionamento, eles não estão totalmente protegidos contra possíveis agentes danificadores do suporte de papel. Nos ambientes do Arquivo, que possui 470 estantes, existe fonte de luz artificial que incide sobre as caixas-arquivo e não há medidas de controle de temperatura e umidade relativa do ar, como arcondicionado ou desumidificador.

Dessa forma, ao analisar os dados obtidos, verificou-se que provavelmente a concentração de agentes biológicos no Arquivo se deve principalmente pela ausência de controle de temperatura/umidade ou, ainda, pela existência de aberturas ou frestas para o ambiente externo. No Arquivo Geral de Cariacica o principal agente químico constatado foi a poeira, que entra em contato com a documentação ocasionando na fragilidade e deterioração dos suportes. Já a ação humana compreende a outro fator de deterioração extrínseca e os documentos com dobras e acessórios de metal indicam danos causados pelo homem.

Sobre a adoção adequada dos princípios da gestão documental pela Prefeitura, pode-se evidenciar que os conjuntos documentais vêm recebendo atenção e cuidado especializado, porém, 
foram constatadas algumas inadequações: dispersão, deterioração de suporte, acúmulo desnecessário, infiltrações ou, até mesmo a perda total de unidades documentais.

\subsection{Novos rumos para o velho dilema da gestão de documentos em Cariacica}

O Arquivo de Cariacica tem vivenciado a inserção de novas Tecnologias de Informação e Comunicação (TICs). Embora se considere a relevância desse movimento, é necessário que os atuais rumos não obscureçam problemas basilares da instituição em pauta, por exemplo, a falta de recursos (financeiros, humanos e de infraestrutura) que muitas vezes podem comprometer as práticas arquivísticas.

Nesse arquivo, que possui uma vasta quantidade de documentos utilizados para prestação de contas aos gestores e cidadãos ou ainda para a manutenção da história da cidade, percebeu-se que algumas caixas já foram destruídas pela ação do tempo ou de infiltrações (penetrações de água nas paredes, teto, piso e demais ambientes); restando apenas fragmentos de documentos.

Os colaboradores da instituição mencionam que a essa possui algumas dificuldades quanto aos seguintes aspectos: controle adequado de temperatura e umidade relativa do ar bem como fornecimento estável de energia elétrica; plano de escoamento e remoção de acervo em caso de emergências; controle de acesso aos ambientes de guarda e de recuperação de documentos; definição de regras precisas sobre acesso às áreas de segurança.

Dessa forma, a gestão do Arquivo e de seus conjuntos documentais deve organizar de forma eficiente, tanto física quanto intelectualmente, a produção, administração, gerenciamento, manutenção e destinação dos documentos. Além disso, agilizar a eliminação de documentos que não tenham valor administrativo, fiscal, legal, histórico ou científico. Por esse encaminhamento, é que se verificam as possibilidades dos usos adequados de novas técnicas para o gerenciamento eletrônico de documentos visando assegurar o acesso à informação onde e quando for necessária aos cidadãos.

Segundo membro da equipe do Arquivo Geral de Cariacica, a gestão documental está funcionando de forma adequada no Município, principalmente após a instituição do Decreto $\mathrm{n}^{\circ}$ 069/2019 e do Decreto n ${ }^{\circ}$ 111/2019. Tais regulamentos subsidiam a criação e implantação de Plano de Classificação de Documentos, Tabela de Temporalidade e Manual de Transferência de Documentos para o Arquivo Público Municipal de Cariacica. Por meio desses instrumentos foram definidas diretrizes para a condução do tratamento documental das secretárias até a destinação ao 
Arquivo Geral de Cariacica, que nos dias atuais tem recebido somente documentos de caráter intermediário.

O Arquivo Público conta ainda com um sistema de gestão de documentos para classificação e recuperação das informações. Mas devido às demandas que existem atualmente, o quadro de pessoal terá que ser aumentado. Nessa via, informações da rede de colabores do Arquivo reportaram que o quadro de pessoal do Arquivo Municipal é deficitário, pois tem somente seis pessoas atuantes (01 Coordenador; 02 Arquivistas; 02 Assistentes Administrativos; e 01 Auxiliar de Serviços Gerais) para atender toda a demanda da Prefeitura de Cariacica e de suas secretárias.

\subsection{Discussão e pontos críticos da gestão documental no arquivo público municipal}

A análise da ambiência do Arquivo Geral de Cariacica viabiliza expor as principais atividades executadas pela instituição, por exemplo: Recebimentos de Documentos, Recolhimento de Documentos Atendidos, Classificação de documentos e a Eliminação de documentos. Dentre esses processos, o Recolhimento de Documentos Atendidos e a Eliminação de Documentos são atividades deficitárias na instituição, que prejudicam o Arquivo Municipal em sua produtividade e na qualidade do serviço oferecido ao seu público que hoje é 100\% interno.

No tange aos aspectos negativos da Instituição, os colaboradores destacaram: i) o quadro de pessoal insuficiente; ii) a necessidade de modernização dos computadores, das mesas e cadeiras da equipe (ergonomia); iii) o software somente para atendimento interno; e iv) a estrutura física precária (iluminação, climatização, desumidificação, vazamento no telhado, limpeza precária, carência de desinfestação e desinfecção.

Em relação aos aspectos contraproducentes da gestão documental detectou-se também que: i) há documento em outra localidade mesmo estando registrado no arquivo; ii) o arquivo está superlotado de documentos; iii) há documentos prescritos, mas que não foram avaliados para a eliminação; iv) não há recebimentos de documentos das secretárias por falta de espaço físico; v) não cumprimento dos prazos prescricionais que estão na tabela de temporalidade documental; vi) o imóvel é alugado e sempre que há necessidade de mudança perde-se a referência das informações ou alguns documentos são danificados.

Quanto aos aspectos positivos ressaltam-se avanços como: i) a implantação do Plano de Classificação, da Tabela de Temporalidade e do Manual de Transferência de Documentos para o 
Arquivo Público Municipal; ii) a criação da Comissão Permanente de Avaliação de Documentos; iii) a implantação do software de gerenciamento de arquivo; iv) o concurso público para contratação de arquivista em 2012.

Pelo exposto, é urgente que sejam feitos esforços para:

- Estabelecer um sistema de informação e digitalização unificado e ágil com dados detalhados para o aperfeiçoamento dos métodos de organização, preservação, acesso e uso;

- Fomentar a destinação de espaço e equipamentos adequados e a contratação de mais profissionais habilitados como passos essenciais para transformar a realidade e o espaço institucional;

- Realizar fiscalização constante sobre o adequado cumprimento das diretrizes previstas em normativas legais e administrativas;

- Propiciar espaços para discussões com a sociedade civil e comissões de gerenciamento e avaliação de documentos para verificação de demandas e realização de quaisquer modificações nos procedimentos de gestão de documentos e atendimento ao público;

- Implementar serviços mais arrojados para contemplar o atendimento ao usuário externo de acordo com a Lei $\mathrm{n}^{\circ} 12.527 / 2011$ para que a população tenha maiores possibilidades de acesso às informações de interesse público.

De certo, a implantação de uma política de gestão de documentos e o treinamento para todas as secretarias são ações que terão resultados em médio e em longo prazo. Para a qualidade e efetividade dessas práticas, é necessário um intenso trabalho para a conscientização dos funcionários da Prefeitura Municipal de Cariacica (PMC) de que o Arquivo "não é simplesmente guarda ou depósito de documento, e sim um organismo vivo para recuperação da informação", como argumenta um dos membros da equipe do Arquivo Geral de Cariacica.

Enfim, o que há para melhorar? Como mencionado, o Arquivo tem uma boa gestão, a localização do prédio é adequada, a gestão de documentos funciona satisfatoriamente. Contudo, o espaço do Arquivo não é suficiente, o prédio não é um adequado para a instalação do arquivo e há a falta de um serviço de malote para facilitar o atendimento às secretarias do Município.

Em meio a tantas questões que requerem soluções, recomenda-se que as decisões sejam definidas com cautela, buscando o diálogoda equipe do Arquivo com demais interagentes: a Gerência de Apoio Logístico para problemas forem de caráter administrativo ou de bens móveis; e Locador do Imóvel para reportar às questões de ordem contratual e de reparos estruturais no 
edifício. Espera-se para o futuro de Cariacica uma boa gestão de documentos por meio de programas que tenham como fundamento os princípios arquivísticos e os dispositivos legais para subsidiarem as melhorias técnicas, tecnológicas e de mediação.

\section{Considerações finais}

Esta pesquisa teve o propósito de analisar, sob o prisma da gestão documental, a realidade arquivística em um contexto municipal na Região Metropolitana da Grande Vitória (RMGV). Portanto, optou-se pelo estudo de caso do Arquivo Geral de Cariacica (ES), buscando identificar alguns procedimentos acerca do tratamento documental na referida instituição.

Cariacica possui um arquivo legalmente instituído e até o momento estabeleceu vínculo somente com um profissional arquivista para trabalhar permanentemente na instituição. A Prefeitura, com pequenos avanços, tem desenvolvido a consciência de que a crescente produção documental deve passar por um trabalho arquivístico adequado. A massa documental do Município se constitui em um vasto acervo de documentos, de valor informacional e testemunhal, que pode ser útil para comprovação de direitos e construção de histórias/memórias da localidade.

O Arquivo Geral de Cariacica possui alguns problemas de natureza física e sua situação é parecida com as encontradas em outras prefeituras conforme os referenciais consultados para a elaboração desta pesquisa. Pelos dados obtidos via rodas de conversas com a equipe da instituição e observações no local, constatou-se que há uma clara evidência da escassez de recursos humanos e financeiros destinados ao Arquivo; o que é sinalizado pelo reduzido quadro de pessoal qualificado. Ademais, esse não detém uma estrutura organizacional bem constituída - em forma de autarquia ou fundação pública - que garanta sua independência/autonomia. Outro fator a ser considerado, é que essa instituição não arresta uma amplitude administrativa e sociocultural condizente com o projeto político, pedagógico e social delineado em seu planejamento.

O caminho para o aperfeiçoamento da Instituição vem sendo formalmente estabelecido e já começou a ser trilhado a partir do momento em que o ente público demonstrou consciência sobre a necessidade de melhor explorar o acervo do Arquivo Geral de Cariacica. Sugere-se que nesse percurso o poder executivo do município tente esquadrinhar e (re)pensar a função social do arquivo para atender o que preconiza a legislação brasileira a respeito dessa pauta. 
Nesse sentido, mediante o exposto pela equipe do Arquivo Geral, infere-se que é necessário: buscar alternativas de treinamento para os funcionários que trabalham no Arquivo; ampliar o quadro de funcionários efetivos; realizar contratações de serviços especializados para digitalização e tratamento de itens documentais com problema de conservação; adquirir equipamentos para a digitalização dos documentos no município; atualizar o mobiliário; realizar reformas no edifício que apresenta problemas estruturais e de climatização; e, idealmente, adquirir uma propriedade para a constituição de sede permanente.

Desta pesquisa até o empoderamento do Arquivo Geral de Cariacica existe um longo caminho, bem como vários obstáculos a serem enfrentados, incluindo a questão financeira e a sede permanente como principais fatores. Para que isso aconteça, é preciso uma ampla mobilização de toda a comunidade, pois a transformação exigida é fundamental para que os recursos investidos na instituição possam, de fato, frutificar. Ou seja, para que os documentos possam ser utilizados para resguardar os princípios da responsabilidade, da prestação de contas e da preservação da memória individual, coletiva e social de uma dada localidade.

\section{Referências}

ARQUIVO NACIONAL (Brasil). Dicionário brasileiro de terminologia arquivística. Rio de Janeiro: Arquivo Nacional, 2005. 232 p. (Publicações Técnicas, 41). Disponível em: http://www. Arquivo nacional.gov.br/images/pdf/Dicion_Term_Arquiv.pdf. Acesso em: 17 nov. 2020.

BARROS, D. S.; AMELIA, D. Arquivo e memória: uma relação indissociável. Transinformação, Campinas, v. 21, n. 1, p. 55-61, abr. 2009. Disponível em: https://www.scielo.br/pdf/tinf/v21n1/04.pdf. Acesso em: 07 nov. 2020.

BRASIL. [Constituição (1988)]. Constituição da República Federativa do Brasil de 1988. Diário Oficial República Federativa do Brasil, Brasília, DF, out. 1988. Disponível em: http://www.planalto.gov.br/ccivil_03/constituicao/constituicao.htm. Acesso em: 27 nov. 2020.

BRASIL. Decreto $n^{\circ}$ 4.073, de 3 de janeiro de 2002. Regulamenta a Lei no 8.159, de 8 de janeiro de 1991, que dispõe sobre a política nacional de Arquivos públicos e privados. Diário Oficial República Federativa do Brasil, Brasília, DF, 04 jan. 2002. Disponível em: www.planalto.gov.br/ccivil_03/decreto/2002/d4073.htm. Acesso em: 28 nov.2007.

BRASIL. Lei Complementar 101. Lei de Responsabilidade Fiscal, estabelece normas de finanças públicas voltadas para a responsabilidade na gestão fiscal e dá outras providências. Diário Oficial República Federativa do Brasil, Brasília, DF, 04 maio 2000. Disponível em: http://www.planalto.gov.br/ccivil_03/leis/lcp/lcp101.htm. Acesso em: 28 dez. 2020. 


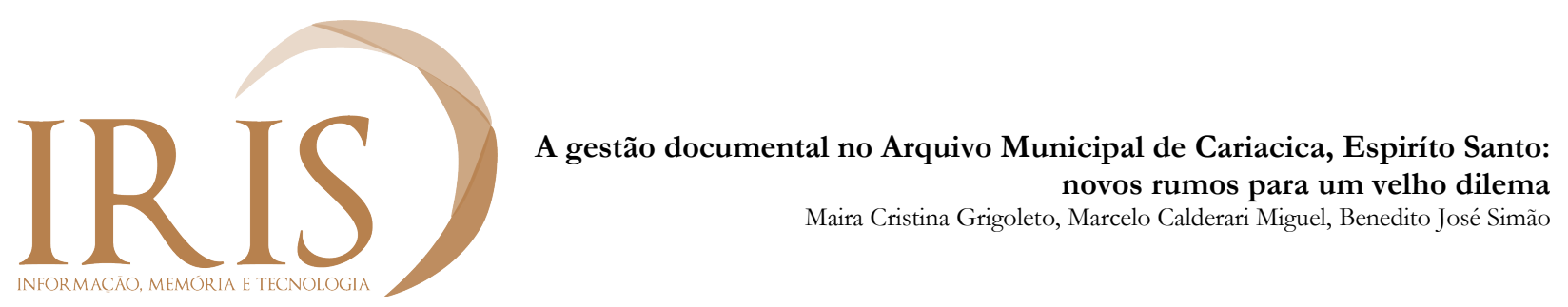

BRASIL. Lei Complementar no 131, de 27 de maio de 2009. Acrescenta dispositivos à Lei Complementar no 101, de 4 de maio de 2000, que estabelece normas de finanças públicas, voltadas para a responsabilidade na gestão fiscal e dá outras providências. Diário Oficial República Federativa do Brasil, Brasília, DF, 27 maio 2009. Disponível em: http://www.planalto.gov.br/ccivil_03/leis/lcp/lcp131.htm. Acesso em: 28 nov.2007.

BRASIL. Lei n. 8.159, de 08 de janeiro de 1991. Dispõe sobre a política nacional de Arquivos públicos e privados e dá outras providências. Diário Oficial República Federativa do Brasil, Brasília, DF, 1991. Disponível em: www2.camara.leg.br/legin/fed/lei/1991/lei-8159-8-janeiro-1991-322180-normaatualizadapl.html. Acesso em: 27 nov. 2020.

BRASIL. Lei n 12.527, de 18 de novembro de 2011. Regula o acesso a informações. Dispõe sobre os procedimentos a serem observados pela União, Estados, Distrito Federal e Municípios, com o fim de garantir o acesso a informações. Diário Oficial República Federativa do Brasil, Brasília, 18 nov. 2011. Disponível em: www.planalto.gov.br/ccivil_03/_ato2011-2014/2011/lei/112527.htm. Acesso em: 5 nov. 2020.

CANALI, H. Arquivo público retorna à sociedade mais moderno e com mais conforto para a população. Secretaria de Planejamento, Pará, 24 out. 2017. Disponível em: http://seplan.pa.gov.br/arquivo$\mathrm{p} \% \mathrm{C} 3 \% \mathrm{BAblico}$-retorna- $\% \mathrm{C} 3 \% \mathrm{~A} 0$-sociedade-mais-moderno-e-com-conforto-parapopula $\%$ C3\%A7\%C3\%A3o. Acesso em: 10 jan. 2021.

CARIACIA (ES). Edital de Chamada Pública no 20/2014. Processo no 33076/2014/SEMAD. [Locação de imóvel pessoa física e/ou jurídica]. Cariacica: Secretaria Municipal de Administração, https://www.cariacica.es.gov.br/wp-content/uploads//2014/10/EDITAL-CHAMAMENTOP\%C3\%9ABLICO-N\%C2\%B020-2014-ALUGUEL-ARQUIVO.pdf

CARIACIA (ES). Decreto n ${ }^{\circ} 111$, de 09 de julho de 2019. Cria a comissão permanente de avaliação de documentos (CPAD) e define suas atribuições. Diário Oficial Do Município, Cariacica, ES, 14 ago. 2019. Disponível em:

www.cariacica.es.gov.br/static/files/diario/DI\%C3\%81RIO\%20OFICIAL\%20MUNICIPAL\%2014-08$2019 \% 20-\% 20 \% 20 \mathrm{EDI} \% \mathrm{C} 3 \% 87 \% \mathrm{C} 3 \% 83 \mathrm{O} \% 20 \mathrm{~N} \% \mathrm{C} 2 \% \mathrm{BA} \% 201139 \% 20-$

\%20MLCOELHO\%20(assinado).pdf. Acesso em: 28 nov. 2020.

CARLI, D. T.; FACHIN, G. R. B. A Lei de Acesso à Informação e a gestão de documentos. Biblios, n. 66, p. 47-59, 2017. Disponível em: http://www.scielo.org.pe/pdf/biblios/n66/a05n66.pdf. Acesso em: 28 nov.2007.

CONSELHO NACIONAL DE ARQUIVOS. Subsídios para a implantação de uma política municipal de arquivos: o arquivo municipal a serviço dos cidadãos. Rio de Janeiro: CONARQ, 2000. 21p.

\section{CONSELHO NACIONAL DE ARQUIVOS. Criação e Desenvolvimento de Arquivos Públicos}

Municipais: Transparência e acesso à informação para o exercício da cidadania. Rio de Janeiro: Arquivo Nacional, 2014. Disponível em:

http://www.conarq.gov.br/images/publicacoes_textos/Cartilha_criacao_arquivos_municipais.pdf. Acesso em: 10 dez. 2021.

CONSELHO NACIONAL DE ARQUIVOS. A Campanha. Campanha de Criação e Desenvolvimento de Arquivos Públicos Municipais. 2020. Disponível em: https://www.gov.br/conarq/pt-

br/assuntos/campanha-arquivos-municipais-publicos/a-campanha. Acesso em: 10 jan. 2020. 


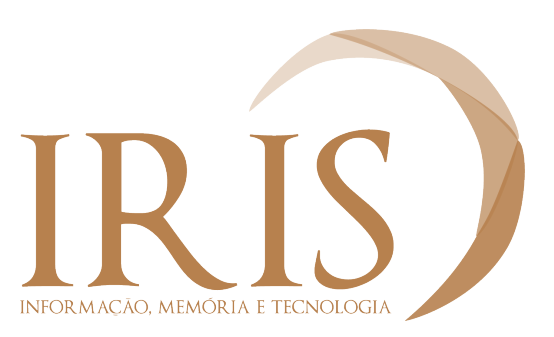

A gestão documental no Arquivo Municipal de Cariacica, Espiríto Santo: novos rumos para um velho dilema Maira Cristina Grigoleto, Marcelo Calderari Miguel, Benedito José Simão

COOPER, D. R.; SCHINDLER, P. S. Métodos de Pesquisa em Administração. 10. ed. Porto Alegre: Bookman, 2011.

CORTES, M. D. F. A Acessibilidade nos Arquivos públicos. 2011. 86 f. Monografia (Especialização em Gestão em Arquivo s) - Universidade Federal de Santa Maria, 2011. Disponível em: https://repositorio.ufsm.br/handle/1/1395. Acesso em: 07 nov. 2020.

FABEN, A.; RODRIGUES, A. C. Identificación de los documentos de archivo em los parâmetros de la diplomática y la tipológía documental. Anuario Escuela de Archivología, XI, p. 161-182, 2019. Disponível em https://revistas.unc.edu.ar/index.php/anuario/article/view/30052/30807. Acesso em: 10 dez. 2020.

FEITOZA, R. A. B.; DUARTE, E. N. Documentos, Arquivo e práticas arquivísticas: bases necessárias à memória no ambiente organizacional. Logeion: Filosofia da Informação, v. 7, n. 1, p. 206-227, set. 2020. Disponível em: http:/ / revista.ibict.br/fiinf/article/view/5420. Acesso em: 07 nov. 2020.

FERNÁNDEZ, J. B. R. La gerencia de informacion: el caso de los archivos. Biblios, v. 4, n. 16, p. 3-13, jun./dez. 2003. Disponível em: http://eprints.rclis.org/5461/1/2003_018.pdf. Acesso em: 07 nov. 2020.

GIL, A. C. Como elaborar projetos de pesquisa. 4. ed. São Paulo: Atlas, 2009. 175 p.

HAIR JUNIOR, J. F.; BABIN, B.; MONEY, A. H.; SAMOUEL, P. Fundamentos de métodos de pesquisa em administração. Tradução Lene Belon Ribeiro. Porto Alegre: Bookman, 2007, 471p.

LORENZI, F. J. Repensando as problemáticas e perspectivas na (re)Implantação de um Arquivo Público Municipal: um estudo de caso do Arquivo Público Municipal de Chapecó - SC. In: SEMINÁRIO DA FUNDAÇÃO ESCOLA DE SOCIOLOGIA E POLÍTICA DE SÃO PAULO (FESPSP), 6., 2017, São Paulo. Anais [...]. São Paulo: USP, 2017. p. 1-25.

MACHADO, H. C; CAMARgO, A. M. A. Como Implantar Arquivos Públicos Municipais. 2a ed. São Paulo: Arquivo do Estado, 2000. 88p.

MACNEIL, Heather. Correntes em transformação. In: EASTWOOD, Terry; MACNEIL, Heather, organizadores. Correntes atuais do pensamento arquivístico. Belo Horizonte: UFMG, 2016.

MINAYO, M. C. S. O desafio do conhecimento: pesquisa qualitativa em saúde. São Paulo: Hucitec/ABRASCO, 1994.

PEDRAZZI; F. K.; PAVÃO, L. S. A importância da implantação de arquivos públicos municipais: estudo de caso da Prefeitura Municipal de Dilermando de Aguiar (RS). Revista Sociais \& Humanas, v. 31, n. 1, p. 169-181. Disponível em: https://periodicos.ufsm.br/sociaisehumanas/article/view/28115/pdf. Acesso em: 10 jan. 2021.

ROCHA, D. L.; SCHMIDT, C. M. D. S. Plano de classificação do serviço de diagnóstico por imagem do hospital universitário de medicina veterinária da universidade federal fluminense: a identificação arquivística como processo intelectual de análise. In: CONGRESSO BRASILEIRO EM ORGANIZAÇÃO E REPRESENTAÇÃO DO CONHECIMENTO, 5., 2019. Anais [...]. Belém: ISKO BRASIL, 2019, p. 226236. Disponível em: http://isko.marilia.unesp.br/index.php/isko/isko/paper/view/121. Acesso em: 22 out. 2020. 
SCHÄFER, M. B.; LIMA, E. S. A classificação e a avaliação de documentos: análise de sua aplicação em um sistema de gestão de documentos arquivísticos digitais. Perspectivas em Ciência da Informação, Belo Horizonte, v. 17, n. 3, p. 137-154, jul./set. 2012. Disponível em:

https://www.scielo.br/pdf/pci/v17n3/a10v17n3.pdf. Acesso em: 08 nov. 2020.

SILVA, L. C. Desafios da implementação da política pública de arquivos: as funções arquivísticas e o acesso à informação na Prefeitura Municipal de Vitória, ES. Orientador: Renato Pinto Venâncio. 2020. 259 f. Tese (Doutorado em Ciência da Informação) - Programa de Pós-Graduação em Ciência da Informação, Escola de Ciência da Informação da Universidade Federal de Minas Gerais, Belo Horizonte, 2020.

TRIVIÑOS, A. N. S. Introdução à pesquisa em ciências sociais. São Paulo: Atlas, 2007.

Data de submissão: 12 de dezembro de 2020.

Data de aceitação: 15 de janeiro de 2021.

Data de publicação: 12 de março de 2021. 